\title{
Harnessing Women's Potential Through Education, Training And Access To Technology To Enhance Food Production And Security In Africa
}

\author{
Never Assan \\ Zimbabwe Open University, Faculty of Science and Technology, Department of Agriculture Management, \\ Bulawayo Region, Box 3550, Bulawayo, Zimbabwe.
}

\begin{abstract}
Women, face a number of interlinked constraints that reduce their agricultural productivity and their ability to use natural resources and sustainably contribute to food production. As a result of this scenario, enhancing food production through gender equality and equity as a means of promoting food security and reduce poverty has been a challenge in Africa. This discussion attempt to explore ways in which gender equality and equity can be achieved in food production.The role of education and training for women, and access to appropriate technology by women in food production are discussed and challenges highlighted as means of promoting food security and reduce poverty. Planning for women's education and training does, in fact, improve the likelihood that women contribute fully to food production, as a result improving households standard of living. Technology may be quite useful in increasing productivity, however access to technology depends on availability and women's resources to purchase such technologies. As women generally have less access to cash and credit, they are less likely to purchase new technologies. Overall, some of the issues of concern to women as food producers are the lack of access to technical training and appropriate technology, in addition to lack of access and control over land, financial resources and cash income. Assisting women in acquiring and use of new technologies in food production is fundamental to agricultural and rural development in Africa. Therefore, with a view to highlighting some of the constraints and enhancing women's capacities in food production, this review will look at lack of education, training and technology as some of the major factors and constraints affecting women's roles in food production.
\end{abstract}

Key words: Women, Education, Training, Technology, Africa

\section{Introduction}

Sustainable food production and poverty reduction in its totality will continue to haunt Africa in the coming decades. Some of the reasons for the inefficient food production systems on the continent has been due to gender inequality, through inadequate education and training for women. This has been exacerbated by women not encouraged to adopt new food production technologies to increase food production. This is on the backdrop that rural women constitute more than a quarter of the world's population, and are dually vulnerable group [1]. The availability of training to ensure that women have the means necessary to participate in efficient food production initiatives and enhance food security has been inadequate. New technologies are often sort without fully understanding the potential for use by women and helping them to participate in food production for poverty alleviation and enhance food security. This lack of consideration often leads to most interventions in training and technologies being inaccessible to women which has result into food insecurity and increased poverty on the continent.However, this does not take into account that involvement of women in food production issues cancontribute to reduced vulnerability, increased food security and accelerated economic growth in Africa [2]. There is consensus that global food production need to be increased in order to cope with the increased human population in Africa. The existence of challenges such as climate change will derail the effort to produce enough food for ever increasing population. The need to invest in education, training and adoption of new technologies by women in order to accrue maximum benefit in food production should be acknowledged. Strategy which focuses on women education and training in food production should be instrumental in ensuring food security. The discussion therefore, concludes that in the planning and implementation of food production issues to enhance food security, intensification of education and training of women is proposed, such that women are uplifted as the custodian of food production. Women should be assisted in adoption of new food production technologies which make them increase their participation in food production and achieving the primary objective which should be food security. The development and training of women is fundamental to accelerating increases in food and agriculture. For many years to come, the bulk of training and extension efforts in agriculture management will have to be concentrated on women who are the custodian of food production, and therefore addressing the perpetual food insecurity on the continent. 


\section{Women education and training could improve food production and security}

It is generally accepted that strategies and programs to alleviate poverty and promote economic development cannot succeed unless the poor themselves are able to participate directly in the development process [3]. Yet there can be no participation without information, and education as the basis for informed and effective local participation. Policy makers and planner are becoming increasingly aware of the crucial contributions of women farmers to food production and food security in Africa. Nevertheless, policies on the whole still do not address the needs of women farmers adequately in terms of education and training. In cases where the roles and needs of women farmers are recognized in policy, these tend not to be adequately translated into appropriate education and training practice in food production for women. This has resulted in education and training in food production issues giving inadequate attention to women farmers and their needs. However, there is a general consensus, for instance, that women and men are often responsible for different food production tasks in both crop and livestock oriented enterprises. Despite this acknowledgement, education and training is generally focused on the improvement of production and technologies for men's crops and tasks, while those of women are neglected. Women's access to education and training opportunities reduces the likelihood of household poverty [4], and resources in educated women's hands have a range of positive outcomes for human capital and capabilities within the household. Women training in food production is an important tool which can be widely utilized in solving the problem of food insecurity [5]. Placing an emphasis on gender sensitivity training and the rights of women will pave way for programs that seek to enhance women equal treatment in food production. A cross country study of developing countries covering period 1970- 1995 found that $43 \%$ of the reduction of hunger that occurred was attributed to progress in women education [6]. Food production and security requires targeted and deliberate action in the form of comprehensive education and training of women with special focus on the resource poor women who are the majority in most African communities. Training courses, which promoted women's capacity for longer-term planning as well as providing practical skills, reported the greatest impact on intra-household relations and participation in the community [7]. Women's relative lack of formal education and high illiteracy rates may have two key consequences in the context of food insecurity. First, women often have limited access to and understanding of modern food production methods and the impending effects of failure to adopt new technologies in food production. Secondly, women are often unable to acquire certain skills that would help increase their food production potential. Women's education alone resulted in a 43 percent reduction in hunger from 1970 to 1995, while women living longer led to an additional 12 percent decline in hunger levels, according to the [2]. Gender stereotypes still abound in education decision-making in SADC; in curriculum and teaching materials, and in the choice of training subjects. This negates the fact that training is desirable, as often women are eager to improve their knowledge and practices, and have their knowledge affirmed by professionals. There is a general agreement on the high priority to be attached to education and training of women in food production as a possible avenue to reduce poverty and enhance food security [8]. Training assumes that the greater interaction of women with the food production activities and their involvement in the development process will increase their capabilities thus will be having positive impact on their food insecurity reduction.

The need to set up community based training programs for women with well defined goals should be one of the future priorities to alleviate poverty and food security. Such forum provides a space for women to share knowledge and experiences in addressing gender within their work, creating a sustainable platform for technical support, problem-solving and new ideas on gender and food production [9]. [10] stated that technical and commercial education broaden the farmers intelligence and lay the basis for vocational training. Community based training enable women to perform farm activities intelligently with full appreciation of their contribution to the final product, which is food production. Women's role has child tenders has reduced opportunities for improving their education and also seeking employment outside the home to acquire an income. On the other hand, acquiring education mean women will have fewer children and improved opportunities for girls and women in employment [11]. Education and training should promote the sharing of expertise with outside experts but at the same time balancing this with local personnel with good knowledge of women's skills and potential in food production. Before embarking upon a program on training as a priority to support women, systematic courses on planned food production should be indentified and women consulted. This should take into account the gender differences and participation of women in different agricultural ventures such as subsistence farming to modern commercial crop and livestock farming. Most Southern African countries have agro-based economies and training in food production at all levels should be aimed at developing women who are the majority for making a living out of agriculture and working in improving household food and support their communities at large. It is logical to assume that training in broad based key factors in food production will increase production and meet the local food demands.

Training women and providing technical equipment in production should be the fundamental bases for acquiring knowledge, skills and techniques for food production management translating into higher productivity and profitability. [12] concluded that education acquired by farmers had a positive influence on farmers labor, 
income and productivity. It is considered, therefore, that the introduction of suitable designed women food programs at community level could serve as a basis for further training, having multiple benefits of bringing potential women into direct contact with realities and problems of food production at an early stage. Women participants from these community based training should be able to apply principles and tools of management for the husbandry of various classes and types of livestock and crops. On completion of women tailor made community based food production programs, women should have been sufficiently equipped with knowledge on concepts of the subject, interrelationship between traditional scientific methods of food production, roles, constraints and strategies associated with increased food productivity. However, consideration needs to be given to more rapid training throughput of women on food production issues to meet the growing demand for food product.

There is need to broaden the curriculum to include mini-livestock species in rural communities for women. In the developed world the direction of food production has changed due to new establishments in biotechnologies. The integration of such issues into the curricula of food production is lacking at tertiary level in most developing countries. Training focusing on aspect of crop and livestock genetic resources, their evaluation and utilization should become an integrated part of training of crop and livestock production specialists who train women. Public policies and investment are biased against women, as a result this has hampered food production.

Development techniques, including training and group formation, can be leveraged to aid in new livelihood development for women living in rural areas who lack the resources necessary for agricultural livelihoods. There is a general agreement on the high priority to be attached to education and training on women as a possible avenue to reduce poverty and enhance food security on the continent. The need to set up gender sensitive training programs for both women trainers and women farmers with well defined goal should be one of the future priorities to alleviate poverty and food security through enhanced food production. It is suggested that technical and commercial education broaden the women farmers intelligence and lay the basis for vocational training. In addition, it enables the women farmers to perform farm activities intelligently and with full appreciation of their contribution to the final product. Education and training should promote the sharing of expertise with male counterparts but at the same time balancing the involvement of women as a group. Before embarking upon a discussion on training as a priority to support women in food production, systematic courses on planned production should be indentified. This should take into account the individual women's potential in their involvement which normally ranges from small subsistence farming to modern commercial farming practices existing side by side. In the past decades the commercial livestock industries have been able to feed the rapidly expanding population although it was involving majority of men with les of women. On the basis of the above mentioned scenario no one will therefore deny the great importance of greater participation of women in food production.

Most African countries have agro-based economies and training women who are the majority in food production at all levels should be aimed at developing a human resource base capable of making a living out of agriculture and working in improving food production related institutions to support the country's economic growth. It is logical to assume that broad based women training is the key factor in developing food production to meet the demands of local populations. Training personnel and providing technical equipment to women in food production should be the fundamental bases for acquiring knowledge, skills and techniques for increased food production and improvement that are needed to enhance food production systems into higher productivity and profitability. [12] concluded that education acquired by farmers had a positive influence on farmers labor and income. It is considered, therefore, that the introduction of suitable designed food production courses at community level could serve as a basis for increased food production. This would have the benefit of bringing potential good women into direct contact with realities and problems of food production at an early stage and will provide an insight into applied food production. Women community based training should be able to apply principles and tools of food production and the husbandry of various classes and types of livestock and crops. On completion of community based food production courses beneficiaries should have been sufficiently equipped with knowledge on concepts of the subject, interrelationship between traditional scientific methods of producing livestock and crops, roles, constraints and strategies associated with these sectors. Various training institutions offer tertiary training courses in conventional livestock and crop production, but non offers community based women specific curriculum. There are also various courses available for farmers in both livestock and crop production, however these programs are not gender sensitive. There is little emphasis on livestock species and crops suited to women such as mini livestock which need less land for production. Women oriented farming should take into account unavailability of land and women's reduced chances of acquiring credit facilities. Consideration needs to be given to more rapid women training throughput on mini-livestock courses to meet the growing demand for animal product. In the developed world the direction of livestock and crop production has changed due to new establishments in biotechnologies. The integration of such issues into the curricula of women oriented community based crop and animal production is lacking in most 
developing countries. Most women farmer trainers are not well versed on issues of new approaches to livestock and crop production. This has created information gaps on food production in general for women, which means a systematic and planned community based courses on new technologies are called for to enhance food production by women. Africa should take advantage of the inventions in livestock and crop biotechnologies which provides a technical and operational framework for assisting women farmers to increase production. The training of new young women scientist in new technologies will expose beneficiaries to the demands and challenges in food production. The failure to increase food production through crop and livestock improvement may be a result of lack of imparting new concepts in food production to women. The introduction of marker assisted food production technologies could be a future strategy for increased production. If the women trainers are to effectively tackle the thorny issue of increased food production, must either be a broadly trained professional with knowledge of sociology, economics, land use planning and integrated rural development as well as food production issues. It has been noted that livestock and crop production programs offered by many governments departments disregard the potential of women as food producers. This aspect need possibly to be addressed by introducing gender sensitive food production curricula, and this should be a prerequisite for an effective extension services. On the other hand, gender imbalance of extension workers has worsened already fragile food systems in Africa. The vast majority of agricultural extension workers are in Africa are male, with the number of women extensionists averaging only 3\%. This represents a serious limitation in the extent to which women farmers are in contact with outside advice on agricultural technologies [13]. Alongside the general neglect of women farmers, the extension services which they do receive are often restrictively stereotyped. Lack of gender analysis, training and problem solving expertise are weak links in extension staff which has resulted in failure to understand the roles that women play in agricultural production. This has been worsened by the curricula of extension methodology content, most of the time do contain sufficient reference to improving extension work with women in food production. Through training and access to appropriate technology women can be empowered to make their own choices and respond to increasing economic opportunities in food production. Investing in the human capital women offer is a key to sustainable and gendersensitive food policy to achieve food security This can be done through education and by removing barriers to the productive use of women's time and energy. Involving more women in food and development processes may require special outreach and training for poorer and less educated women and for those who hesitate to voice their needs in front of men for cultural reasons.

\section{Technology and infrastructure development may incentivize women to produce more food}

Women are the leading source of food production, and realize that empowering women in modern farming technologies is the best way to achieve increased food production. Targeting women in agricultural technology dissemination can have a greater impact on poverty than targeting men [14]. Technological innovations if employed appropriately will continue to allow food production to keep pace with population growth and the rising food demand in Africa. Technology adoption of high yielding crops and high productive livestock has witnessed success in food production. Farmers, especially women, are the direct and everyday users of land and water, and are those most in need of new technologies, information, and services (such as credit) that can increase their productivity and conserve scarce resources. The unbridled use of technology to improve efficiency in food production and ultimately, women's interests is the most effective components of enhancing food production and security. However, in spite of abundant modern technologies and guidelines available from the developed world for use in increasing food production, most of the women who constitute the majority in food production ventures cannot adopt these new innovations. This has resulted in failure to produce enough food for individual households and communities at large. When women adopt new agricultural technologies, they directly experience the effects of agricultural research. Adoption can depend on whether the technologies make women less vulnerable; whether women have the assets to adopt the technologies; the nature of disseminating institutions; and cultural factors, such as gender roles [15]. Non gender sensitive policies have militated against women in adoption of new technologies. State sponsored research institutions should be part of the drive for technological innovation and food production and security. Encouraging women to adopt new technologies is another way to help women in Southern Africa become a bigger force in farming.On station production units may provide the centers for rapid distribution of superior plant food and livestock genotypes through improved technologies, which as [16] states, are area model for the role of sophisticated technology in improving livestock breeds and developing food production systems. The results of new developments in reproductive physiology which makes various manipulations possible opens up entirely new horizons for livestock and crop genetic resources improvement. New technology can achieve immediate improvement through selection of foundation livestock and crop populations and attain faster and more effective performance improvement rates in both crops and livestock genetic resources. Technology based schemes offer effective options to maintain and improve crops and livestock if well functioning infrastructure and capital are provided 
to women. The introduction of biotechnological techniques such as crop and livestock gene banks would be ideal but unrealistic under the current constraints of developing countries. Women may benefit as technological advances reduce unit costs of production and hence increase profits. However, the existing research facilities fall far short of what is required for livestock and crop improvement to enhance food security by women. Ttraditional agricultural research and development systems are not gender-responsive and typically do not consult female farmers and end-users, improved varieties and technologies do not take into account women's needs, preferences and resources [17]. Most research facilities have lived up to their life span and are dilapidated which warrant massive reconstruction to effectively contribute to women's potential in food production. This has made these institutions inappropriate as they are confined to obsolete methods of crop and livestock improvement to increase food production.

Establishment of links between public and private sector to support women in food production has been constrained by the inability to economically justify the benefit on such a move by individual countries [18]. Public and private sector partnership in new food production approaches, remain a theoretical possibility considering the lack of appropriate facilities, the extent of inadequate human resource development and expertise. This exacerbated with the absence of formal marketing facilities for crops and livestock has contributed to the persistence of comparatively widespread household food insecurity. Food production in the developed world has advanced to the current stage mainly due to the presence of good technology, infrastructure and joint public and private sector support in food production [19]. While advancement in infrastructure has improved food production efforts in developed countries, lack of proper infrastructure has hampered food production and perpetuated food insecurity in Southern Africa. However, the need for appropriate infrastructure is paramount for successful processing, distribution and storage of food by women.

\section{Implications}

Strategies to alleviate poverty and improve food security will not be successful unless issues relating to women as custodians of food production are taken into account. The major issues revolve around women's education, training and access to appropriate technologies in food production. It is clear that if women are supported and trained in the basics of sustainable food production skills, our perpetual food insecurity problems in Africa would be solved. Therefore, it is high time that gender training perspective must be introduced in the agricultural and food production curriculum or programmes. A significant problem is that in many food production programmes, in-service training and education in extension methodology there is insufficient examination and discussion of the roles of women in agricultural production and rural development. Too little time allocated to gender analysis and a participatory approach aimed at solving the problem of how extension work can effectively be carried out taking into account the crucial role of women in food production with rural women. Although women play a major role in food production in Africa, agricultural information is not effectively reaching and benefiting this vulnerable group in the food security chain. Gender sensitive policy initiatives like the training of women to address specific concerns and priorities of women in food production should be adopted. Appropriate technologies which are efficient and easy to use by women should be developed and trainings for operation in food production should be the basis of food production goals. Food production strategies should be gender sensitive and should empower women in their quest for maximum contribution to food production. More capacity building and training programs should be developed to empower women and equip them with the right food production skills and practices. It is quite clear that women's participation and contribution to food production is critical. However, they are often neglected in education and training of food production issues. This has serious negative implications for food production and overall poverty alleviation strategies on the continent. Therefore, it is imperative to address the question that whether a turnaround in food production is possible in Africa without focusing on the education and training of women so that they can fully participate in food production. This also particularly point towards women's access to appropriate technologies to increase productivity. The lack of visibility of women's contribution and participation in food production has emanated from social, economic and cultural impediments which need to be addressed. If these areas are addressed, will provide a platform for development of gender sensitive policies which gives adequate attention to women farmer's needs in terms of education and training. Taking into account gender differentials in the curricula and training of extensionists who could effectively relate to women results in women benefiting most from training and extension services. Extension workers who train women should be awareness of the needs of women through training to work with women. Suggest that the training and information provided by women facilitators will be transferred to other women's in their groups effectively than men. The access of women to new food production technologies is constrained by their lack of access to adequate finances to buy these technologies, but also by gender blind policies in the development and adoption of new appropriate technology which do not take into account the needs and priorities' of women in general. Appropriate technologies which are effective and easier to manage by women, can help ensure that women, whose participation in food production is essential for food security and alleviate poverty, retain their central 
role as custodians of food production and security. In most communities women farmers are engaged in a wide range of laborious tasks related to food production and security, as a result any attempt to develop and introduce appropriate labor saving technologies in food production will go a long way enhancing the capacity of women to contribute to food production. The involvement of women in food production can be enhance through adequate training and provision of appropriate technologies, and therefore the importance of gender to household food security emphasized. Of paramount, is the need to reorient the agricultural curricula in many African countries, trainers should continually assess and revise the curricular content and methods, as new information becomes available from gender research sources, and as the needs of the women also change. Curriculum development and reorientation is best served by using iterative, flexible approaches that enable the curriculum to respond to the changing needs and resource constraints of both gender. Empowering women through training and access to appropriate technology have a greater impact on families and communities if women empowered it increase the their ability to generate income and saving the respective countries at large, therefore alleviating food insecurity in the process and giving them chance to take charge and improving local economies. Given the increased continental attention on food crisis, stakeholders interested in supporting meaningful food production and security interventions should be made better aware that women's empowerment is a core issue for gainful solutions. Investing in women education and training will bolster food productivity, reduce hunger and promote economic growth. Investments in training and appropriate agricultural technology will enhance women's capacities to ensure that more food is produced to feed the growing continent's population.

\section{References}

[1]. Food and Agricultural Organization of the United Nations (FAO), Women, Agriculture and Rural Development.Corporate Documents Repository, Economic and Social Development Department.A synthesis report of the Near East Region Adapted from Human Development Report and Country Papers, UNDP, 1994.

[2]. Food for All: Investing in Food Security in Asia and the Pacific - Issues, Innovations, and Practices. Asian Development Bank (ADB) book, January 2012.

[3]. Oakley, P. et al. Projects With People: The Practice of Participation in Rural Development. Geneva, International Labour Office, $1991.284 \mathrm{pp}$.

[4]. Kabeer N, Women's economic empowerment and inclusive growth: Labour markets and enterprise development. School of Oriental and African Studies, UK, SIG Working Paper 2012/1.

[5]. Gross, R, Schultink, W, Kielmann, AA, Community nutrition: definition and approaches.Encyclopedia of human nutrition. Ed. by M. Sadler, S. Strain and B. Caballero.Academic Press, London, UK, 1998.

[6]. von Grebmer, K., B. Nestorova, A. Quisumbing, R. Fertziger, H. Fritschel, R. Pandya-Lorch, and Y. Yohannes. 2009. 2009 Global Hunger Index: The challenge of hunger: Focus on financial crisis and gender inequality. Bonn, Washington, DC, and Dublin: Deutsche Welthungerhilfe, International Food Policy Research Institute, and Concern.

[7]. Kabeer, N, Noponen, H, 'Social and economic impacts of PRADAN's Self Help Group Microfinance and Livelihoods Promotion Program: analysis from Jharkhand, India' Imp-Act Working Paper No. 11, IDS, Brighton www.ids.ac.uk/impact/publications/working ᄀ_papers.html, 2004.

[8]. Adebayo, J, 1997 Educating women in Northern States. The Nigeria Tribune, April 2, 1997.

[9]. Kanesathasan A, Jacobs K, Young M, Shetty A 2013 A Capturing the gender effect: Guidance for gender measurements for agriculture programs.International Center for Research on Women, 2013.

[10]. Adekunle, A, 1978. Modern analysis economics. Ibadan, Aromolatan Publishing, Nigeria pp 12-13.

[11]. Galor, O, Weil, DN, The Gender Gap, Fertility and Growth. The American Economic Review 86(3):374-387.Garcia, M., A. Pence, and J. Evans. 2008. (eds). Africa's Future, Africa's Challenge: Early Childhood Care and Development in Sub-Saharan Africa. Washington, DC: World Bank, 1996.

[12]. Stewart, F, Employment, income distribution and development (Frankcass, 1975), 1-157.

[13]. Commonwealth Secretariat. (1992). Women, Conservation and Agriculture: A Manual for Trainers. London, Commonwealth Secretariat Women and Development Programme, P204.

[14]. Alderman H, Hoddinott J, Haddad L, Udry C (2003) "Gender Differentials in Farm Productivity: Implications for Household Efficiency and Agricultural Policy," in Household Decisions, Gender, and Development: A Synthesis of Recent Research, ed.A. Quisumbing, IFPRI, 2003.

[15]. Quisumbing A 2003 "What Have We Learned from Research on Intra-household Allocation?" in Household Decisions, Gender, and Development: A Synthesis of Recent Research, ed. A. Quisumbing, IFPRI, 2003.

[16]. Smith, C, Rates of genetic change in farm livestock. Res. Dev. Agric. 1984, 1, 79- 85.

[17]. Quisumbing A, Pandolfelli, L, Promising approaches to address the needs of poor female farmers. Paper provided by International Food Policy Research Institute (IFPRI) in its series Research briefs with number 13.2033 K Street, NW, Washington, DC 20006, 2003. http://www.ifpri.org/sites/default/files/publications/in13.pdf.

[18]. Hanekom D 1998. Agricultural Policy in South Africa, Ministry for Agriculture and Land Affairs, Private Bag X116, Pretoria, 0001 .

[19]. International Food Policy Research Institute (IFPRI) 2011. Global Food Policy Report: Major Food Developments in 2011. 